$\int_{15}^{8} / 91052$

\title{
Performance Relationship Diagrams
}

\section{Kansas City Division}

\author{
M. J. Cary \\ KCP-613-4567
}

Published November 1991

Prepared for the United States Department of Energy Under Contract Number DE-AC04-76-DP00613. 


\section{DISCLAIMER}

This report was prepared as an account of work sponsored by an agency of the United States Government. Neither the United States Government nor any agency thereof, $r$ ur any of their employees, makes anv warranty, express or implied, or assumes any legal liability or responsibility for the accuracy, cor pleteness, or usefulness of any information, apparatus, product, or process disclosed, or repres'snts that its use would not infringe privately owned rights. Reference herein to any specific comme,rcial product, process, or service by trade name, trademark, manufacturer, or otherwise, does not necessarily constitute or imply its endorsement, recommendation, or favoring by the United States Government or any agency thereof. The views and opinions of authors expressed herein do not necessarily state or reflect those of the United States Government or any agency thereof.

Printed in the United States of Amerisa.

This report has been reproduced from the best available copy.

Available to DOE and DOE contractors from the Office of Scientific and Technical Information,

P. O. Box 62, Oak Ridge, Tennessee 37831; prices available from (615) 576-8401, FTS 626-8401.

Available to the public from the National Technical Information Service, U. S. Department of Commerce, 5285 Port Fioyal Rd., Springtield, Virginia 22161. 
Distribution

\section{PERFORMANCE RELATIONSHIP DIAGRAMS}

M. J. Cary

Published November 1991

Technical Communications

Kansas City Division 


\section{Abstract}

By describing a business function's cost drivers and graphically depicting the interrelated cost drivers serving as controls and resources to them, a visual performance model can be provided. A graphical technique, called performance relationship diagraming, has been devised that logically describes these cost drivers and their interrelationships.

\section{COST DRIVERS}

A cost driver is an entity which, through its existence and subsequent priority, volume, or complexity, creates work. There are three classes of cost drivers:

- root cause cost drivers,

- branch cause cost drivers, and

- destination cost drivers.

Root cause cost drivers are the sources of all resulting work for an enterprise. These drivers originate from both external and internal customer requests.

Branch cause cost drivers are the downstream products of root cause cost drivers and, in turn, become sources of further resulting work. These drivers are generally internal to the enterprise and their subcontractors or suppliers.

Destination cost drivers are the ultimate downstream products of all root and branch cause cost drivers. Destination cost drivers become the measurements of service to the enterprise's external customers.

Each of these cost driver classes can be broken down into three categories: control cost drivers, resource cost drivers, and process cost drivers. Of these, control cost drivers are most critical to performance of the enterprise. These cost drivers are measurements of the operating policies, procedures, and requirements for the enterprise and its subordinate business functions. They can originate from requirements that are internal, external, or both.

One feature of control cost drivers is unique. Each control cost driver has a rating, or weight, assigned by the appropriate management entity. This weight is based on the importance or priority placed on each of the enterprise's operating policies, goals, and requirements. Based on the perceived priority, the weights assigned to different control cost drivers may vary significantly. These weights play an important role in providing resources (people, facilities, equipment, funding, and others) and 
determining the volume and complexity of the work to be performed. As a result, control cost drivers have the most significant effect on the overall performance ability of the enterprise and its business functions.

Resource cost drivers are measurements of the resources applied to enable the enterprise and its business functions to perform. The existence, volume, and complexity of resource cost drivers originate predominantly from control cost drivers and their applied weights.

Process cost drivers generally are measurements of a business function's ability to perform its work. The ability to perform quality work in a timely and cost-effective manner in accordance with performance goals will be determined predominantly by the impact of control cost drivers and the resulting volume and complexity of the resource cost drivers.

\section{PERFORMANCE RELATIONSHIP DIAGRAMS}

One method of identifying, describing, and interrelating the cost drivers of an enterprise is performance relationship diagrams (PRDs). Once PRDs are available, the most significant cost drivers can be identified as performance measurements. Basically, PRDs are graphical representations of the various cost drivers and how they relate to each other, as shown in Figure 1.

The diagraming conventions used to draw the conceptual example in Figure 1 are similar to the modeling techniques used in CASE (Computer-Aided Software Engineering) data flow diagraming, particularly the IDEF modeling techniques. Each level of an enterprise and its business functions has its own PRD; in the example, all incoming and outgoing cost drivers external to that business function level are shown with dotted lines. Thus, the set of all PRDs for the enterprise nest within each other, just as departments and their sections within the business functions nest within the enterprise.

Other CASE tools such as data flow diagrams and entity relationship diagrams depict what business function processes are occurring and the information and interrelationships required to perform these processes. Going beyond those tools, the PRDs depict the reasons behind the existence, priority, or complexity of each business function process; in addition, PRDs provide a view of the reasons behind the volume of work content in each business function process.

Using existing CASE tools to design new information systems, for example, without the benefit of PRDs could result in information system designs that automate and provide computer assistance for the existing volume and complexity of each business function's processes. Some simplification might occur, but no existing mechanism will facilitate the qualitative and quantitative impact that process simplification for one business function level will have on all downstream business function levels within the enterprise. 
However, if PRDs are used, particularly in concert with other CASE tools, the performance and resulting impacts of each business function's operations are logically and systematically identified. Resulting impacts on all related business

functions within the enterprise can be identified quickly and measured in common terms. Measuring in cost per year, for instance, can aid in cost benefit analyses for justifying business function or enterprise operation simplification.

The diagraming processes and techniques used to create example PRDs exist and seem to be directly applicable. Further, it appears that PRDs could be fully integrated into the CASE tool set to provide the final link to performance.

\section{APPLICATION}

Performance relationship diagrams may be used to identify, describe, and interrelate the cost drivers of any enterprise engaged in any business. Figure 2 shows a segment of the PRD for a business function named "Design Systems." This example shows the relationships existing for the specific application called "Design Requirements." By describing some of the easily identifiable design cost drivers and contemplating their causes and effects, identification of additional cost drivers, along with their own causes and effects, occurs easily. By categorizing these cost drivers as control, resource, or process cost drivers, the impact that control cost drivers have on resource cost drivers and the resulting process cost drivers becomes visible and measurable. For example, the weight placed on the control cost driver "priority on design" has a direct relationship with the resource cost driver "design tools available," which ultimately impacts the process cost driver "design work effort required." The higher the weight given to "priority on design," the more effective the "design tools available" will be and the less "design work effort (hours) required" will be. By continuing this process, a complete picture of the potential effectiveness of "designing systems" can be logically depicted. Creating PRDs for all business function levels within an enterprise will provide the most complete piciure 


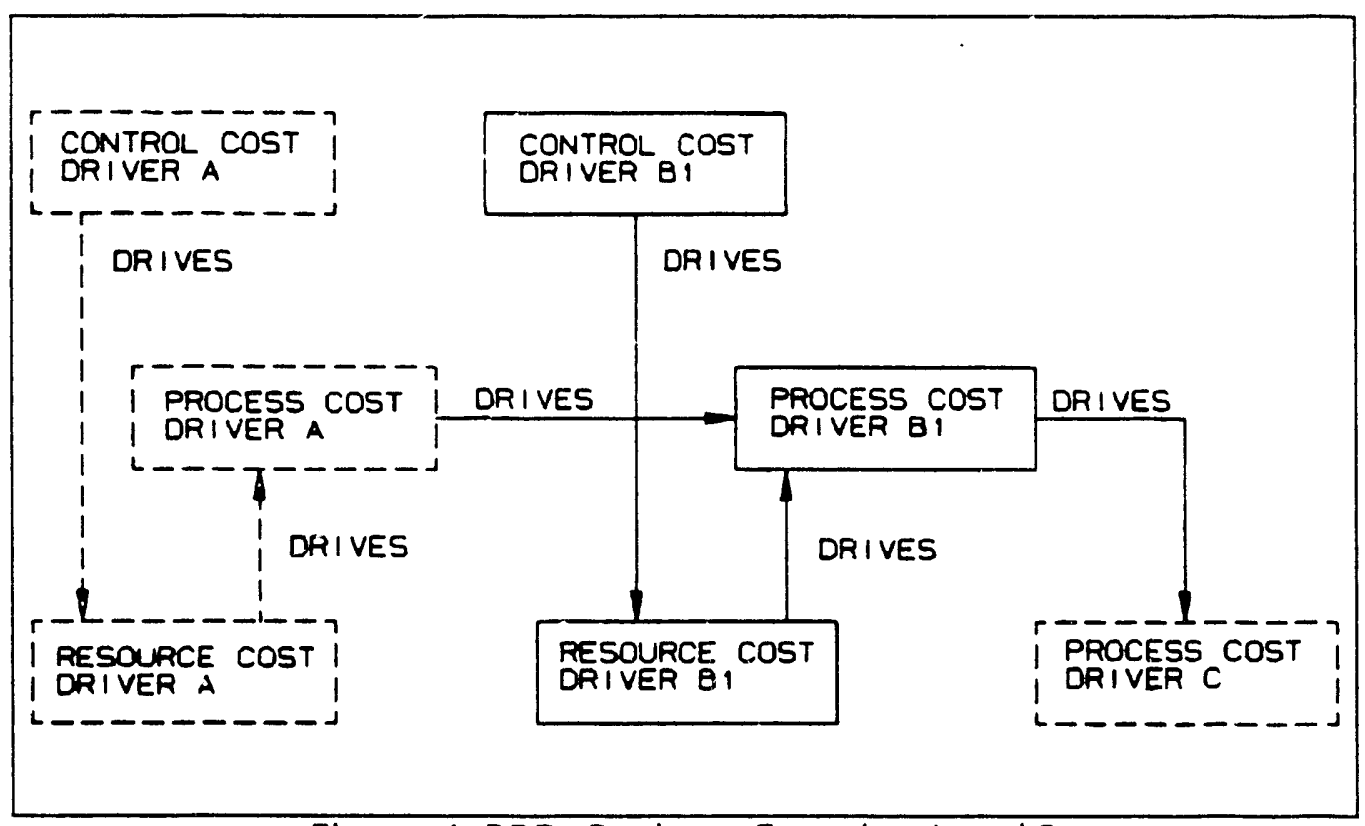

Figure 1. PRD: Business Function Level B

of the enterprise. There is a hierarchy to PRDs that reflect the business function and respective data flow diagrams hierarchy. For example, "design for manufacturability" is a performance goal and a weighted control cost driver for the business function "design product." However, based on the product being designed and its unique performance measurement characteristics such as the number of critical design features, processing complexity, and resultant cost, the weights applied to subordinate design control cost drivers like "design for reworkability," "design for ease of assembly," "design for ease of procurement," or "design for speedy customer delivery" may vary substantially.

These differing subordinate design control cost drivers may represent opposing goals. However, by creating PRDs for lower business function levels, all subordinate weighted control cost drivers within the enterprise can be identified. Design tradeoffs among opposing applicable cost drivers internal or external to the enterprise can be qualitatively and quantitatively understood and negotiated. The resulting optimum design can then be more quickly identified as one which optimizes the achievement of all applicable enterprise weighted control cost drivers while minimizing the impact on all applicable enterprise resource and process control drivers.

The impact of changes in any cost driver at any business function level can be identified qualitatively from the PRD itself and quantitatively through actual performance measurements. By coupling the PRDs with their respective business functions and data flow diagrams, changes to business function operations and data flow can be directed at root cause cost driver points of inefficiency. Performance changes in the downstream business function processes and data flows will appear in the performance measures, based on the PRDs. 


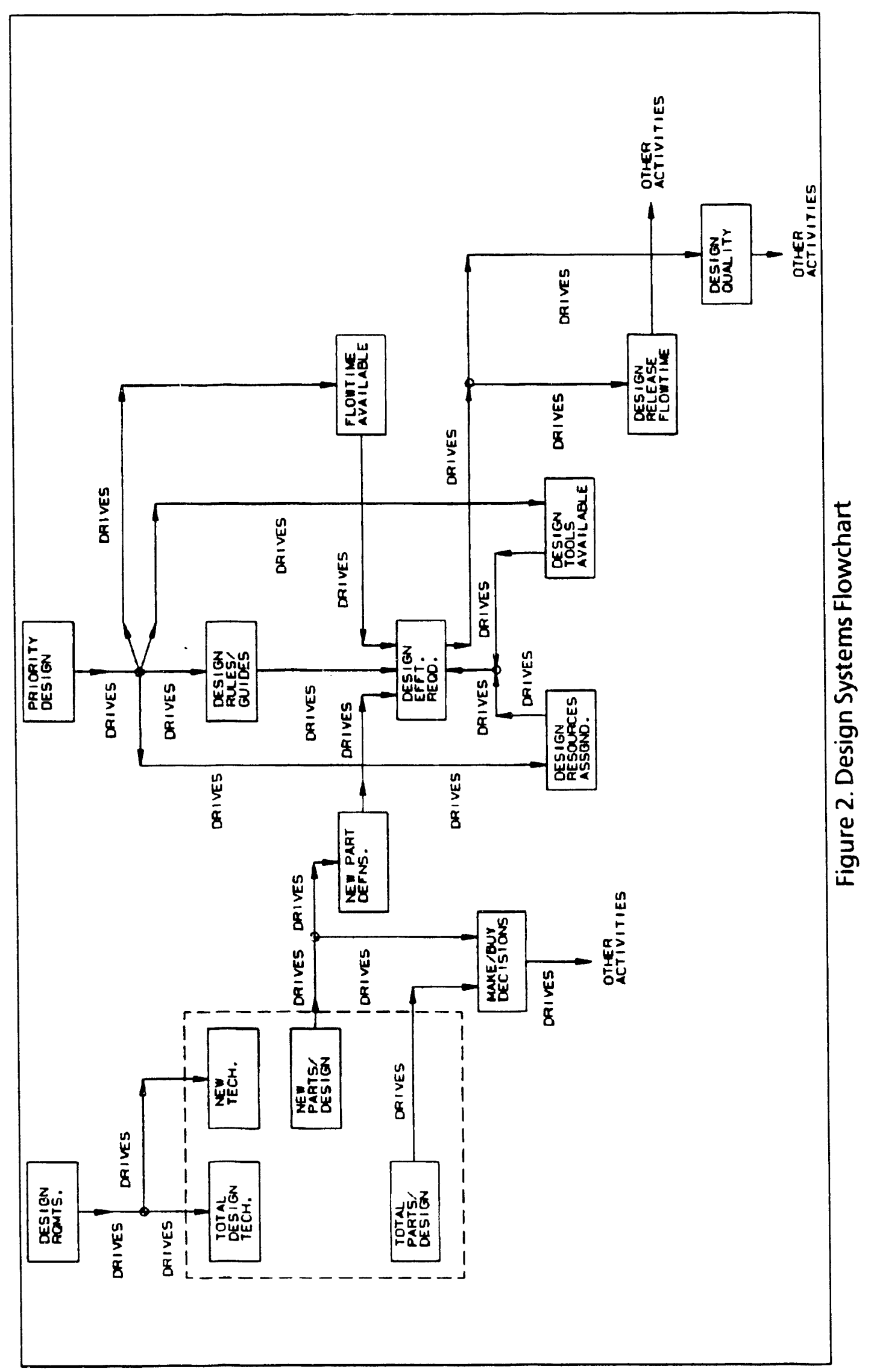




\section{IMPLEMENTATION EXAMPLES}

\section{Management Resource Planning Example}

Because the "number of customer orders" and the "order input system complexity" affect the "accuracy" and "quality of schedules," in theory the number of customer orders could be reduced by as much as $75 \%$ by entering orders for each design system end use and then "exploding" these orders against a mission design system end use bill of material. In essence, this type bill of material already exists, but some additional resource effort would be required to maintain it in a more usable bill of material format.

The overall impact of using the PRD concept would be a significant reduction in "customer order input work effort," "customer order input flowtime," and "number of people required for customer order input." In addition, an accompanying significant increase would be realized in "schedule accuracy" and "schedule change timeliness." These latter two sost drivers are branch control cost drivers for business functions like "procure product" and "build product."

\section{Corporate Resource Planning Example}

Presently, management resource planning and project management are two separate information systems. The next logical step would be to integrate these systems into a single corporate resource planning system using PRDs. Under such a concept, all work performed within the enterprise would be associated with a customer order project and would have a "bill of activities," with each activity having an "activity specification."

The bill of activities would identify and number all the activities necessary to accomplish each project undertaken by the enterprise. Much of the work by business functions, like "design product" or "procure product," relate to existing customer orders. Additional customer orders would be created for all other enterprise work. Each bill of activities would then be matched to the one or more applicable customer orders.

The "activity specification" file would identify the business function responsible for each numbered activity, the work effort required, flowtime, and other related information. This information would be estimates based on actual data provided by the performance measurement database, an extension of the PRDs. With these mechanisms, project and resource planning for all enterprise workload by business functions is created by "explosions." The resulting visibility of all enterprise projects will allow the business functions to schedule their work more effectively. Also, schedule and cost performance for all projects undertaken by all business functions within the enterprise can be measured individually, as well as summarized to enterprise level performance. With the creation of a corporate resource planning system, project and resource planning for all work within the enterprise becomes a reality, making world-class enterprise performance an attainable goal. 

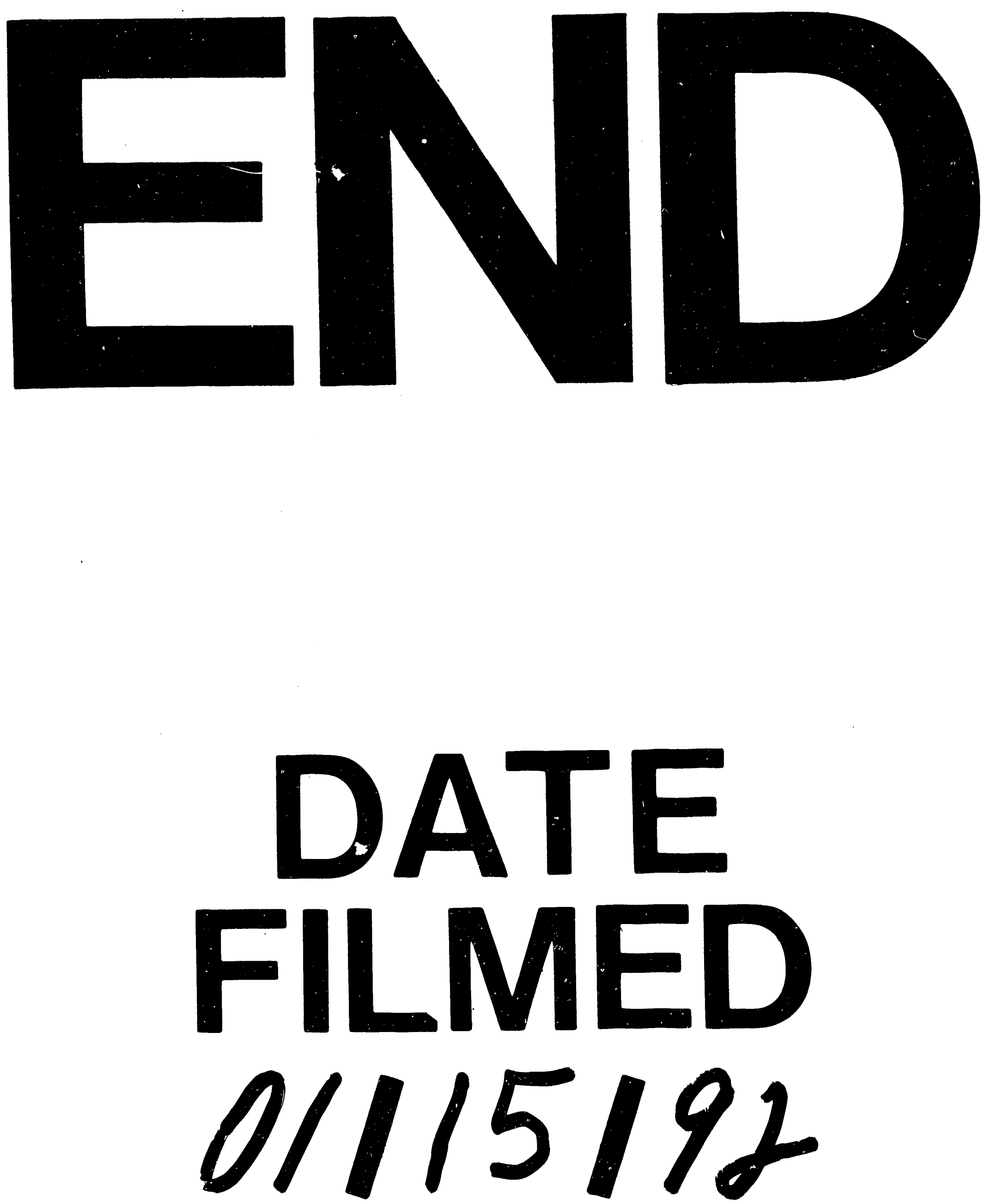
